\title{
The effect of mobile phone use on hearing on pure tone audiometry
}

\begin{abstract}
Introduction: Mobile phones as fastest means of communication, indispensable for daily life globally. The widespread use has given rise to concerns about the potential health hazards of its electromagnetic fields (EMFs) on human health. The present study was conducted to investigate the adverse effects of mobile phone usage on auditory functions and to study the pattern of hearing threshold in mobile phone users.
\end{abstract}

Objective: The objective of the study was to study the effect of mobile phone on average pure tone audiometry (PTA) threshold of the person and to study the changes in the pure tone threshold at high frequencies such as $2 \mathrm{kHz}, 4 \mathrm{kHz}$, and $8 \mathrm{kHz}$ among the students with prolonged exposure to mobile phones.

Material and methods: A cross-sectional study was conducted among 200 medical and paramedical students who have been using mobile phones for one year or more, divided in two groups. Group A- less than one hour per day and GroupB- more than one hour per day. The effect of mobile phones on the PTA threshold in the exposed ear and the nonexposed ear was also assessed.

Results: The study shows that there is a significant difference in average air conduction (AC) and bone conduction (BC) hearing threshold among the exposed and the nonexposed ears $(P<0.05)$ especially at high frequency. A significant rise of both $\mathrm{AC}$ and $\mathrm{BC}$ threshold in group B more than group A also noted in this study.

Conclusion: The study conducted shows changes in the hearing threshold with mobile usage. The technology along with comfort also brings some hazards, hence to limit the duration of usage of mobile phones.

Keywords: electromagnetic radiation, harmful effect, hearing threshold, mobile phones, pure tone audiometry
Volume 12 Issue 2 - 2020

\author{
Priya Malik,Aditi Singla, Raman Wadhera, \\ Navdeep Gupta \\ Department Of Otolaryngology, Pgims University, India
}

Correspondence: Priya Malik, Department Of Otolaryngology, Pgims University, India, Tel 9992848642 ,

Email Drpriyamalik09@gmail.com

Received: March 02, 2020 | Published: April 27, 2020

\section{Introduction}

Mobile phone is a modern device used for making and receiving telephone calls over a radio link while moving around a wide geographic area, by communicating with a nearby base station provided by a mobile phone operator, which connects it to the main phone network. ${ }^{1}$ Global system for mobile (GSM) communications, the world's most popular standard for mobile telephony systems, operate in a number of different carrier frequencies, Mobile phones transmit and receive signals using electromagnetic fields microwave range of the radiofrequency band. The widespread use of mobile phones has been growing over the past decade and now is an essential part of business, commerce, and society. ${ }^{2}$

Exposure to electromagnetic radiations in the microwave range emitted from mobile phones threaten people's health, the thermal effects caused mainly by holding the mobile close to the body are headache, sensation of burning or warmth in the ear, burning sensation in the facial skin and alteration in the blood-brain barrier and the nonthermal effects include modification of sleep patterns, an increase in blood pressure, effects on cognitive function, burning and tingling sensation in the skin of the head and extremities, fatigue, dizziness, loss of mental attention and memory retentiveness, headache, malaise, disturbances of the digestive system. ${ }^{3}$ In 2011, International Agency for Research on Cancer (IARC) classified mobile phone radiation as Group 2B - possibly carcinogenic. ${ }^{4}$ The inner ear is probably the first organ that receives the full impact of electromagnetic radiations due to its close proximity. The auditory system and particularly the cochlear outer hair cells are known to be highly sensitive to a great variety of exogenous and endogenous agents and permanent damage may occur to them as these don't have regenerative properties. Therefore, the ear is at risk of exposure to noise from the mobile phone as well as the electromagnetic radiation waves emitted by the phone. ${ }^{5} \mathrm{WHO}$ main concern is the fact that any adverse health effect is entrenched from mobile phone use will be a global concern as developing countries are establishing this technology in preference to the more expensive fixed line systems. The study was designed to study the effects of the mobile phone on hearing threshold.

\section{Materials and methods}

The Cross-sectional and observational study conducted on 200 non-randomised subjects of either sex for a period of two years was conducted between April 2014 and November 2015. Medical and paramedical students aged 18 to 35 years, who were using mobile phone for 1 year or more were enrolled in the study. All subjects with history of chronic ear disease, chronic upper respiratory infection, ototoxic drug intake were excluded. All users of Bluetooth devices, 
portable music players and hands free devices were also excluded. Subjects using both ears equally for conversation on mobile phone were excluded. Informed and written consent was taken from every subject prior to being included in the study. The subjects were assessed on the basis of a preformed questionnaire which elicited information on demographic characteristics (e.g., birth year, gender) and identified the ear (right or left) typically used for making and receiving calls, total duration of mobile usage in a day and total duration of mobile usage in years. Subjects were divided into two equal groups: Group A- using mobile for less than $1 \mathrm{hr} /$ day for 1 year or more and Group B - using mobile for more than $1 \mathrm{hr} /$ day for 1 year or more. Symptoms related to mobile phone usage like tinnitus, sensation of warmth in and around ear, headache etc. were asked for. Detailed clinical examination was performed including a general systemic examination and thorough examination of the ear using otoscope. The three standard tuning fork tests (Weber's, Rinne's, and absolute bone conduction tests) were done. Pure tone audiometry (PTA) was performed bilaterally on study participants of both the groups at frequencies 250, 500, 1000, 2000, 4000 , and $8000 \mathrm{~Hz}$.

\section{Statistical methods}

Analysis was carried out using SPSS (Statistical Package for Social Studies) for Windows version 17.0. Data was analysed by using Student t-test and Chi-square test. All tests were performed at $5 \%$ level of significance, thus an association was significant if the $p$ value was less than 0.05 .

\section{Results}

Maximum number of cases were between 18-20 years age; 60 cases in group A and 37 cases in group B. Mean age of group A was $20.45 \pm 1.55$ and in group B, it was $21.85 \pm 2.81$ years (Table 1). Overall males were 108 and female were 92. Group A had equal number of males and females and in group B, 58\% were males and $42 \%$ were females. In both the groups, right ear was dominantly used with $90 \%$ in group A and $91 \%$ in group B. Among symptoms asked, tinnitus was present in 7\% cases of group B with none in group A, warmth in 5\% cases of group A and in $14 \%$ cases of group B, headache in $5 \%$ cases of group B and earache in $8 \%$ cases each in both the groups (Figure 1).

Table I Age distribution

\begin{tabular}{lll}
\hline Age range (years) & Group A n(\%) & Group B n(\%) \\
\hline I8-20 years & $60(60 \%)$ & $37(37 \%)$ \\
$21-22$ years & $31(31 \%)$ & $28(28 \%)$ \\
$23-24$ years & $7(7 \%)$ & $16(16 \%)$ \\
$25-26$ years & $2(2 \%)$ & $11(11 \%)$ \\
$>26$ years & 0 & $8(8 \%)$ \\
Mean $\pm S D$ & $20.45 \pm 1.55$ & $21.85 \pm 2.81$ \\
Range & $18-26$ & $18-31$ \\
Statistical significance & $<0.001 \mathrm{HS}$ & \\
\hline
\end{tabular}

\section{SYMPTOMS RELATED TO MOBILE USAGE IN BOTH GROUPS}

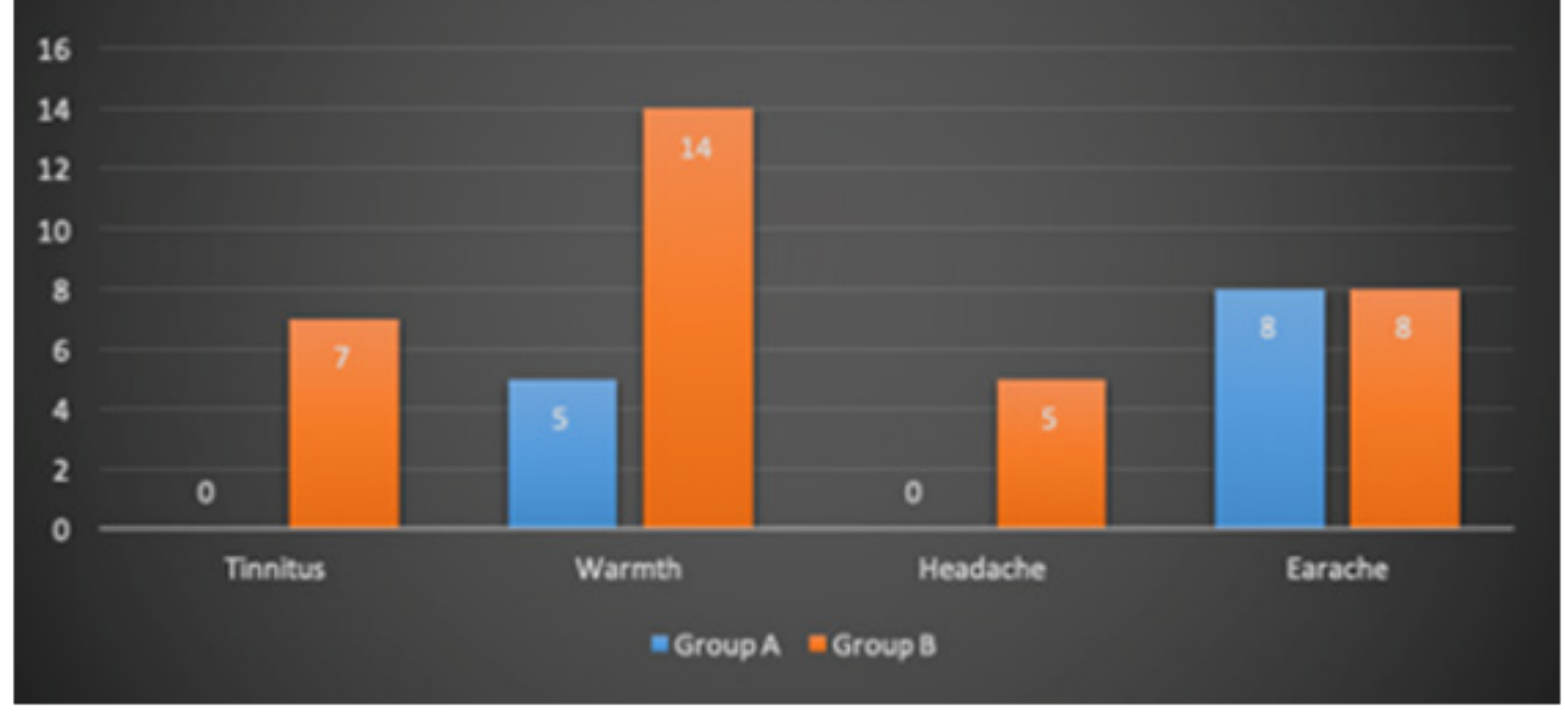

Figure I Symptoms related to mobile usage in both groups.

In group $\mathrm{A}$, mean duration mobile usage minutes per day of $22.5 \pm 10.16$ minutes was observed. In group B, mean of $135.6 \pm 73.17$ minutes per day was noted. In group A, $91 \%$ cases were using mobile for less than 30 minutes per day and $9 \%$ were using mobile for more than 30 minutes. Similarly, in group B, $44 \%$ cases were using mobile for $61-90$ minutes; $26 \%$ for $91-120$ minutes; $9 \%$ for $121-150$ minutes; $11 \%$ for $151-180$ minutes and $10 \%$ with more than 180 minutes per day. Statistical comparison of both the groups showed very high significant difference $(\mathrm{p}<0.001)$ (Table 2). In group A, mean duration of all the subjects who were using mobile for many years was $3.65 \pm 1.45$ years with a range of 1-10 years and in group B, it was $3.92 \pm 2.18$ with a range of $1-12$ years. On analysing statistically, no significant difference was observed between two groups $(\mathrm{p}>0.05)$ (Table 3) (Figure 2). 
Table 2 Mean comparison of air conduction (dominant ear) in both groups

\begin{tabular}{llll}
\hline Air conduction & $\begin{array}{l}\text { Group A } \\
\text { Mean } \pm \text { SD (dB) }\end{array}$ & $\begin{array}{l}\text { Group B } \\
\text { Mean } \pm \text { SD (dB) }\end{array}$ & $\begin{array}{l}\text { Statistical } \\
\text { significance }\end{array}$ \\
\hline $250 \mathrm{~Hz}$ & $19.95 \pm 2.30$ & $20.45 \pm 1.75$ & 0.08 \\
$500 \mathrm{~Hz}$ & $19.8 \pm 2.12$ & $21.1 \pm 2.31$ & $<0.001$ \\
$1000 \mathrm{~Hz}$ & $19.15 \pm 2.36$ & $20.2 \pm 1.40$ & $<0.001$ \\
$2000 \mathrm{~Hz}$ & $19.65 \pm 1.91$ & $20.25 \pm 2.28$ & $<0.05$ \\
$4000 \mathrm{~Hz}$ & $20.25 \pm 3.28$ & $21.15 \pm 4.42$ & 0.104 \\
$8000 \mathrm{~Hz}$ & $20.25 \pm 3.12$ & $23.3 \pm 6.75$ & $<0.001$ \\
\hline
\end{tabular}

Table 3 Mean comparison of bone conduction (dominant ear) in both groups

\begin{tabular}{llll}
\hline Air conduction & $\begin{array}{l}\text { Group A } \\
\text { Mean } \pm \text { SD (dB) }\end{array}$ & $\begin{array}{l}\text { Group B } \\
\text { Mean } \pm \text { SD (dB) }\end{array}$ & $\begin{array}{l}\text { Statistical } \\
\text { significance }\end{array}$ \\
\hline $250 \mathrm{~Hz}$ & $10.3 \pm 1.71$ & $11.1 \pm 3.14$ & $<0.05$ \\
$500 \mathrm{~Hz}$ & $9.95 \pm 1.32$ & $11.30 \pm 3.22$ & $<0.001$ \\
$1000 \mathrm{~Hz}$ & $10.35 \pm 1.62$ & $11.15 \pm 2.64$ & $<0.01$ \\
$2000 \mathrm{~Hz}$ & $12.3 \pm 2.60$ & $12.65 \pm 3.05$ & 0.384 \\
$4000 \mathrm{~Hz}$ & $9.7 \pm 3.39$ & $13.05 \pm 4.76$ & $<0.001$ \\
$8000 \mathrm{~Hz}$ & $10.25 \pm 2.39$ & $13.50 \pm 6.76$ & $<0.001$ \\
\hline
\end{tabular}

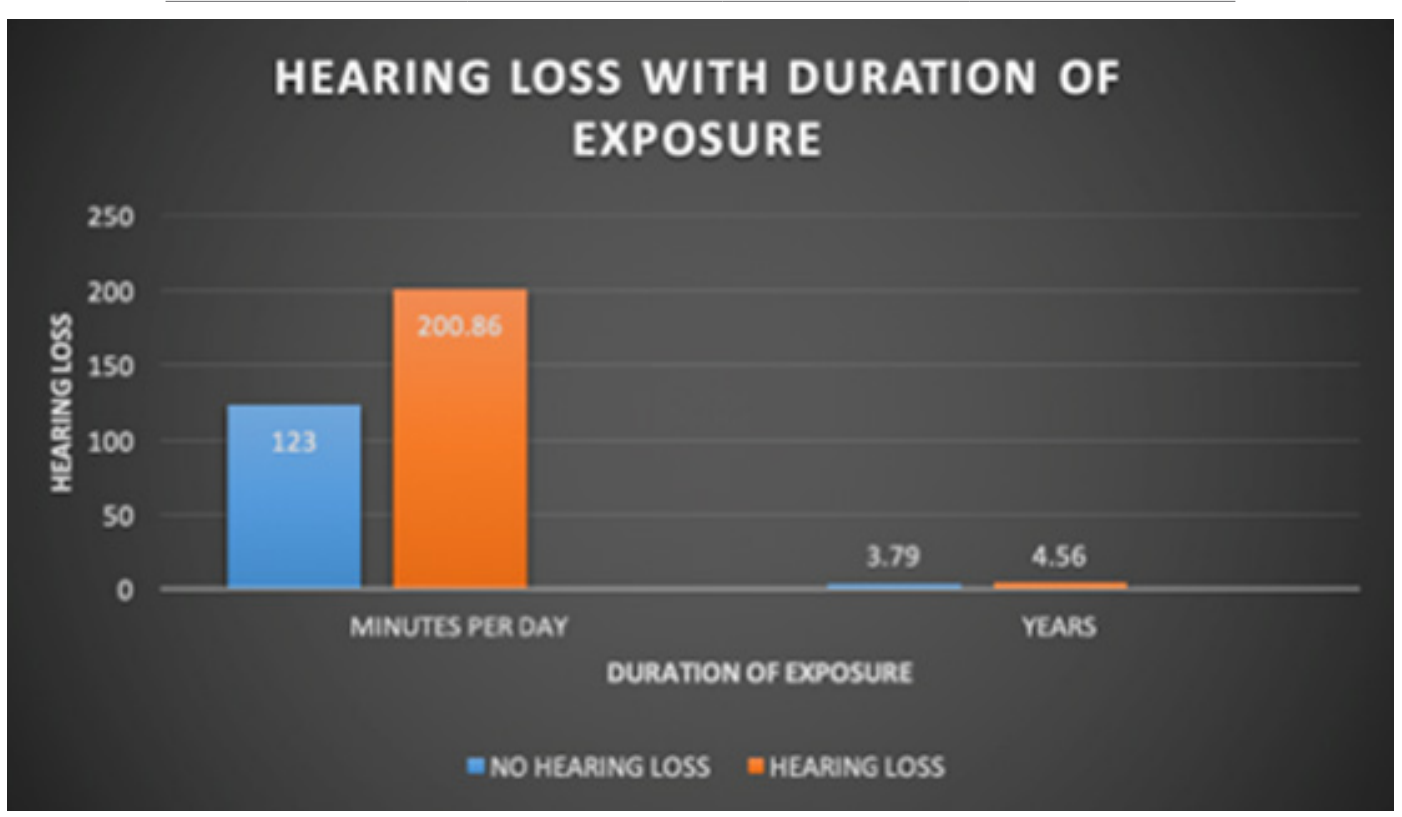

Figure 2 Hearing loss with duration of exposure.

In group A $2 \%$ cases had hearing loss. Amongst subjects who were using mobile up to 30 minutes, 1 case suffered from high frequency mild SNHL and 1 subject in $>30$ minutes duration group had high frequency SNHL. In group B 16\% cases suffered from various type of hearing loss. Out of these, 7 subjects were found in $>180$ minutes/ day usage group closely followed by 4 cases in 151-180 minutes/day usage group and 3 in 61-90 minutes/day group. On statistical analysis, the difference in mobile usage per day in minutes of subjects with hearing loss compared with subjects without hearing loss was found to be statistically significant ( $\mathrm{p}<0.01)$ ( Table 4$)$.
In group A $2 \%$ cases showed hearing loss, using mobile for 5-6 years, 1 case was found to have high frequency mild SNHL and 1 case among $>8$ years had high frequency SNHL. Whereas in group B 16\% cases showed hearing loss, using mobile for $1-2$ years, 1 case was found to have high frequency mild SNHL; 3-4 years duration group had 7 cases with mild SNHL; 5-6 years duration group had 5 cases with mild SNHL and 2 cases with moderate SNHL; and $>8$ years duration had 1 case with mild SNHL. 
Table 4 Number of subjects with and without hearing loss in two groups

\begin{tabular}{lllllll}
\hline $\begin{array}{l}\text { Duration } \\
\text { (minutes) }\end{array}$ & $\begin{array}{l}\text { Group A } \\
\mathbf{n}(\%)\end{array}$ & $\begin{array}{l}\text { Normal } \\
\text { subjects n(\%) }\end{array}$ & $\begin{array}{l}\text { Hearing } \\
\text { loss }\end{array}$ & $\begin{array}{l}\text { Group B } \\
\mathbf{n}(\%)\end{array}$ & $\begin{array}{l}\text { Normal } \\
\text { subjects n(\%) }\end{array}$ & $\begin{array}{l}\text { Hearing } \\
\text { loss }\end{array}$ \\
\hline Up to 30 & 91 & 90 & 1 & 0 & 0 & 0 \\
$30-60$ & 9 & 8 & 1 & 0 & 0 & 0 \\
$61-90$ & 0 & 0 & 0 & 44 & 41 & 3 \\
$91-120$ & 0 & 0 & 0 & 26 & 24 & 2 \\
I21-150 & 0 & 0 & 0 & 9 & 9 & 0 \\
I5I-180 & 0 & 0 & 0 & 11 & 7 & 4 \\
$>180$ & 0 & 0 & 0 & 10 & 3 & 7 \\
Total & 100 & 98 & 2 & 100 & 84 & 16 \\
Statistical sign. & $<0.00 \mid$ Highly significant & & & & \\
\hline
\end{tabular}

Mean comparison of air conduction of dominant ear was observed at various frequencies i.e. $250,500,1000,2000,4000$ and $8000 \mathrm{~Hz}$ in both the groups. At $250 \mathrm{~Hz}$ and $4000 \mathrm{~Hz}$, no significant difference was observed but at $500 \mathrm{~Hz}, 1000 \mathrm{~Hz}, 2000 \mathrm{~Hz}$ and $8000 \mathrm{~Hz}$, a significant statistical difference among two groups was noted. Whereas mean comparison of bone conduction of dominant ear observed at various frequencies i.e. $250,500,1000,2000,4000$ and $8000 \mathrm{~Hz}$ in both the groups. at $250 \mathrm{~Hz}$, we observed a significant difference between two groups. In group A at $250 \mathrm{~Hz}$, it was $10.3 \pm 1.71$ and in group B, it was $11.1 \pm 3.14(\mathrm{p}<0.05)$. Similarly, at $500 \mathrm{~Hz}, 1000 \mathrm{~Hz}, 4000 \mathrm{~Hz}$ and $8000 \mathrm{~Hz}$ we noticed significant difference $(\mathrm{p}<0.01$ and $<0.001)$. No significant difference was noted at $2000 \mathrm{~Hz}$.

\section{Discussion}

The widespread use of mobile have raised concerns about the possibility that exposure to the RF fields from mobile phones or their base stations could affect people's health, particular concern to the WHO is the fact that, developing countries are establishing this technology in preference to the more expensive fixed line systems..$^{6-12}$ Keeping in view the hazards of the mobile phones, the present study was designed to investigate the association of use of mobile phones and hearing loss. In our study, mean age was found to be $20.45 \pm 1.55$ years in group A and $21.85 \pm 2.81$ years in group B. Patel et al., ${ }^{6}$ reported mean age was $26.17 \pm 2.65$ in study group and that of controls was $26 \pm 3.93$ years. ${ }^{5}$ Velayutham et al., ${ }^{9}$ reported mean age to be 27 years. ${ }^{6}$ Ramya CS et al., ${ }^{7}$ study had mean age in test group as $18.2 \pm 1.5$ years and in controls as $17.2 \pm 2.1$ years. ${ }^{7}$ Sahoo et al reported Mean age to be 32 years. ${ }^{2}$ In our study, group A had an equivocal sex distribution while group B had $58 \%$ males and $42 \%$ females which was similar to study by Hegde et al. ${ }^{8}$ Ramya et al., ${ }^{7}$ had a male preponderance with $80 \%$ males in test group and $72 \%$ in control group. ${ }^{7}$ Velayutham et al., ${ }^{9}$ had a distribution of $53 \%$ males and $47 \%$ females. ${ }^{9}$ Sahoo \& Sebastian also reported a male dominance with $62 \%$ males and $38 \%$ females. ${ }^{2}$ Majority of subjects had a preference to use right ear with $90 \%$ in group A and $91 \%$ in group B. Ramya et al., ${ }^{7}$ had similar results with a right ear usage of $88 \%$ in test group and $76 \%$ in control group. ${ }^{7}$ Velayutham et al., ${ }^{9}$ also documented a right ear predilection in $63 \%$ subjects, followed by left in $22 \%$ and no ear preference in $15 \%$ subjects. ${ }^{9}$ Mean call duration was $22.5 \pm 10.16$ minutes in group A and $135.6 \pm 73.17$ minutes in Group B, Statistically significant ( $<<0.001)$. Patel et al documented a mean duration of $106 \pm 40.73$ minutes in study group and $9.33 \pm 3.65$ minutes in control group. ${ }^{6}$ Velayutham et al., ${ }^{9}$ also noted a statistically significant difference in usage time between no hearing loss group $(17.4 \pm 13.6 \mathrm{~min} /$ day $)$ and hearing loss group (40.8 $\pm 24.2 \mathrm{~min} /$ day). ${ }^{9}$ In a study by Hegde et al., ${ }^{8} 35 \%$ cases had $1-2$ hours exposure, $41.7 \%$ had 2-3 hours exposure and $23.3 \%$ had $3-4$ hours of exposure to mobile phones per day. ${ }^{8}$

In present study, mean duration of mobile usage in years in group A was $3.65 \pm 1.45$ and in group B it was $3.92 \pm 2.18$ years with no statistical significance. $(\mathrm{p}>0.05)$. Patel et al., ${ }^{6}$ showed a mean total year usage in study group to be $2.93 \pm 1.36$ years and in control group it was $3.10 \pm 1.06$ years, statistically insignificant. ${ }^{6}$ Hegde et al. ${ }^{8}$ showed mean year of exposure in study group to be 2.47 years while in control group it was 0.12 years, statistically significant. ${ }^{8}$ In present study, 5 $\%$ subjects in group A and $14 \%$ in group B reported warmth in and around ear during mobile phone usage. Tinnitus and headache were reported in $7 \%$ and $5 \%$ of subjects respectively in group B while both were altogether absent in all of the subjects in group A. Earache was reported of $8 \%$ each in both the groups. Hegde et al, ${ }^{8}$ reported blocked sensation (15\%) followed by tinnitus $(10 \%)$ and difficulty in hearing $(3.3 \%)$ to be the main symptoms in the study group and none in control group ${ }^{8}$ Sahoo et al., ${ }^{2}$ reported 5\% cases with tinnitus and $4 \%$ cases with vertigo, ear discomfort in $10 \%$ and fullness in $8 \%$ cases. $^{2}$ Meo et al., ${ }^{10}$ reported $34.59 \%$ with impaired hearing, earache, and/or warmth in the ear. ${ }^{10}$

When dominant ear compared with non-dominant ear, both air and bone conduction thresholds were found to be significantly increased. Similar to Velayutham et al., ${ }^{9}$ and Patel et al., ${ }^{6}$ study. Ramya et al found no significant difference. ${ }^{7}$ In present study out of 16 cases in group B and 2 in group A, both the cases with hearing loss. Hegde et al., ${ }^{8}$ demonstrated that none of the subjects in the study group suffered from significant hearing loss $(>25 \mathrm{~dB}) .{ }^{8}$ In the study by Velayutham et al., ${ }^{9} 38 \%$ cases had hearing loss $>20 \mathrm{~dB}$ in frequencies between 250 $\mathrm{Hz}$ and $16000 \mathrm{~Hz}$. It was concluded that longer usage of mobile daily and longer duration of years can predispose to high frequency hearing loss. ${ }^{9}$ Patel et al suggested that there was some hearing impairment in long term mobile phone users compared to infrequent users. ${ }^{6}$ Sahoo and Sebastian's study reported 3 subjects to have SNHL, suggested to be directly related to duration of mobile phone usage. ${ }^{2}$ Oktay and Dasdag study reported increasing degree of hearing loss over the span of 12 months. Furthermore, suggested phone usage for more than 60 minutes a day had a worse hearing threshold than those who used it less than that, ${ }^{11}$ similar results were reported by Al-Abduljawad, 
Callejo and Kerekhanjanarong et al., ${ }^{12}$ where cases showed an increase in hearing threshold showed. ${ }^{12}$

\section{Conclusion}

The present study shows an increase in the hearing threshold of the ear exposed to the prolonged use of mobile phones. It is not known whether this threshold shift is temporary or permanent. Scientific data are lacking on the molecular and biochemical alterations caused by the EMRs in the organ of Corti. Definite conclusions on the effect of mobile phones on the auditory function can only be derived from studying the ultrastructure of the cochlea and the hair cell after prolonged exposure to the mobile phones. As such this area provides an interesting avenue for further research.

\section{Acknowledgments}

None.

\section{Conflicts of interest}

The author declares that there is no conflict of interest to disclose.

\section{Funding}

None.

\section{References}

1. Heeks R. Meet Marty Cooper - the inventor of the mobile phone. BBC. 2008;41:26-33.

2. Sahoo GC, Sebastian H. Prevalence of sensorineural deafness in habitual mobile phone users. Indian J Otol. 2011;17(3):97-100.
3. Luria R, Eliyahu I, Hareuveny R, et al. Cognitive effects of radiation emitted by cellular phones: The influence of exposure side and time. Bioelectromagnetics. 2009;30(3):198-204.

4. Baan R, Grosse Y, Lauby-Secretan B, et al. WHO International Agency for Research on Cancer Monograph Working Group. Carcinogenicity of radiofrequency electromagnetic fields. Lancet Oncol. 2011;12(7):624626.

5. Shayani Nasab M, Safavi Naiianni SA, Fathol Alolomi MR, et al. Effects of mobile telephones on hearing. Acta Medica Iranica. 2006;44(1):46-48.

6. Patel H, Qureshi R. Effects of long term use of mobile phones on hearing status of healthy individuals compared to infrequent mobile phone users in age group of 15-40 years. Int J Sci Res. 2013;2(11):177-179.

7. Ramya CS, Karthiyanee K, Vinutha S. Effect of mobile phone usage on hearing threshold: A pilot study. Indian J Otol. 2011;17(4):159-61.

8. Hegde MC, Shenoy VS, Kamath PM, et al. Mobile phones: Its effect on hearing. Indian J Otol. 2013;19(3):122-126.

9. Velayutham P, Govindasamy GK, Raman R, et al. High- frequency hearing loss among mobile phone users. Indian J Otolaryngol Head Neck Surg. 2014;16(1):S169-172.

10. Meo SA, Al-Dreess AM. Mobile phone related hazards and subjective hearing and vision symptoms in the saudi population. Int J Occup Med Env Health. 2005;18(1):45-49.

11. Oktay MF, Dasdag S. Effects of intensive and moderate cellular phone use on hearing function. Electromagn Biol Med. 2006;25(1):13-21.

12. Garcia Callejo FJ, Garcia Callejo F, Pena Santamaria J, et al. Hearing level, intensive use of mobile phones. Acta Otorhinolaryngol Esp. 2005;56(5):187-191. 